COLLABORATION BETWEEN SERVICES

Most of the children $(60 \%)$ were referred by social services. This reflects the policy of involving social workers at an early stage in allegations of child abuse. The police referred $22 \%$ of cases. These referrals, usually for child sexual abuse, were made after consultation between police and social workers and involved an examination carried out jointly by a paediatrician and police surgeon.

\section{COST IN TIME}

Altogether $94 \%$ of the children were seen between the hours of 9 am and $9 \mathrm{pm} ; 75 \%$ were seen between $9 \mathrm{am}$ and $6 \mathrm{pm}$. Most of the examinations were carried out with prior arrangement so that children would not have to wait to be seen and investigations by the social services could be completed. Every effort was made not to examine children late in the evening, but sometimes distraught parents were insistent that their child be examined without any delay. Sometimes social services and police found it difficult to complete their investigations until the family were returned home from work or school.

Senior staff in the accident and emergency department saw $81 \%$ of the children which took 206 hours of clinical time, not accounting for time taken in writing reports, attending case conferences, and court appearances. This time commitment by medical staff needs to be taken into account when staffing levels in such a department are reviewed.

\section{FINANCIAL COST}

To provide a separate location for assessing victims of possible child abuse inevitably involves expense. The Rainbow Centre is a purpose designed area which fulfils the Department of Health guidelines of interagency cooperation in child abuse cases ${ }^{7}$ in aiming to provide a sympathetic and peaceful atmosphere where the children can be examined and where their problems can be discussed with the police and social workers and doctors'. 8 Bamford and Roberts state that examinations for child sexual abuse 'should be conducted in absolute privacy in an environment where the child can be comfortable." 9 The centre allows for a single joint examination by relevant staff in a room suitably equipped for all types of examination, 'so that the number of examinations to which a child is subjected is kept to a minimum'. ${ }^{10}$ Although $70 \%$ of cases needed no further investigations, tests carried out on the other children were expensive (total £2133). The tests requested out of hours increased the cost of each request threefold.

The minimum annual costs to this hospital of $£ 63500$ take no account of capital costs to provide the centre and its maintenance. Further uncosted expenses include attendance at case conferences, court appearances, and the time taken in preparing reports for these. The police incur the costs of forensic examinations and of attendance of the police surgeon at examinations. The costs to the hospital have not included any medical treatments required by the children. The cost of follow up with counselling and other support has not been estimated.

\section{CONCLUSION}

The diagnosis and investigation of child abuse is a difficult and important area of paediatrics. It is expensive, not only in financial terms but also in time. This work is done by experienced staff; in the RLCH $82 \%$ of child abuse work in the six month study period was done by senior casualty staff. To ease this burden on two or three members of staff the suspected cases of nonaccidental injury are now seen by paediatric medical registrars under the supervision of their paediatric consultant. Child abuse is demanding in time and energy of staff of the welfare agencies and in particular the social services. It is important to develop and maintain a multidisciplinary approach in a suitable setting such as the Rainbow Centre, but the financial and time commitment by medical staff and their institutions needs to be acknowledged and given support.

1 Skuse DH. Emotional abuse and neglect. $B M 7$ 1989;298: 1692-4.

2 Skuse DH. Emotional abuse and delay in growth. $B M \mathcal{F}$ 1989;299:113-5.

3 Meadow R. Munchausen syndrome by proxy. $B M \mathcal{I}$ 989;299:248-50.

4 Nicol AR. Role of the child psychiatry team in child abuse. $B M \mathcal{F}$ 1989;299:451-2.

5 Department of Health and Welsh Office Publication. Working together. London: HMSO 1991

Meadow R. Epidemiology of child abuse. BMF 1989;298 727-30.

The Rainbow Centre. The Rainbow Centre leaflet. Liverpool: The Royal Liverpool Children's Hospital, 1990.

8 Creighton SJ, Noyes P. Child abuse trends in England and Wales 1983-87. London: NSPCC, 1989.

9 Bamford F, Roberts R. Child sexual abuse I. BMF 1989;299:312-3.

10 Department of Health. Diagnosis of child sexual abuse. Evidence for doctors. London: HMSO 1988.

\section{Commentary}

Child protection work is difficult to cost as the task is a multiagency one. The medical time involved is only one part of the overall expense. Summers and Molyneux have audited the cost of medical examination in units in their hospital. During the six month study period a diagnosis of abuse was confirmed in 48 out of 181 referred children. For a catchment area of total child population 227954 this seems a low figure given that Liverpool has areas of severe urban deprivation. The absence of cases of neglect diagnosed during this period is surprising and reminiscent of figures produced for Glasgow in the 1980s. ${ }^{1}$

There is apparently a low level of confirmation of diagnosis, especially in the suspected sexual abuse cases $(26.5 \%$ of total referrals, $13 \%$ of sexual abuse referrals confirmed). However it is not clear what model of diagnosis is being used or what happened to the 60 children referred with suspicions of sexual abuse where the diagnosis was 'not confirmed'.

The question has to be asked whether the social services and police in Liverpool are poor in their selection of cases referred, or whether 
doctors are over cautious in diagnosis. In Leeds in 1989 there were 823 referrals to paediatricians for suspected abuse or neglect. This included 475 children with suspected sexual abuse in which a definite or probable diagnosis was made in 237 children. $^{2}$

Joint medical examination by a paediatrician and police surgeon was introduced at the time of Cleveland. The method has never been properly evaluated but is used in Liverpool (and some other centres) for sexual abuse cases and oddly in some cases of physical abuse (non-accidental injury) where criminal investigations are likely to proceed. Many cases of non-accidental injury were seen by paediatricians alone, the examination took on average a little longer than a joint examination, and a positive diagnosis was substantially more likely. It cost the tax payer less, as there was only one doctor to pay. It must be time to assess the joint examination as it may be an ineffective (in terms of diagnostic accuracy), expensive, and sometimes inconvenient practice $(25 \%$ of examinations were performed after $6 \mathrm{pm}$, but it is unknown how many were joint). Whatever the reason, sexual abuse diagnosis in Liverpool as judged by these data has yet to get off the ground.

Although comparisons are always difficult, recent incidence studies in the USA suggest that approximately $1 \%$ of American children will experience some form of sexual abuse each year. ${ }^{3}$ That sort of incidence would give Liverpool or Leeds 2000 cases per year. Obviously child protection starts with the family, the community, and school. Doctors often come at the end of a line of other professionals who may respond to the child's difficulties.

Summers and Molyneux remind us that protecting children is costly, but with the numbers seen are they getting good value from the staff of the Rainbow Centre? Referral has increased rapidly in recent times, but much unmet need remains and to what level we do not know. There has not been the increase in staffing medically which this expansion deserves. The authors have shown that above all the work takes time. Paediatric middle grade staff can be used to absorb some of this work but they need training, supervision, and support from consultants if the work is to be done well.

In addition to the initial medical examination and investigation, medical time is spent in case conferences, attending court, in follow up (it is not clear how this is done in Liverpool), reexamination, and treatment (psychological/ physical).

Recently there have been attempts to put a price tag on the consequences of child abuse for society, again in the USA. With increasing evidence of the long term consequences accumulating, it seem likely that this will amount to very much more than our current expenditure on intervention. ${ }^{4}$ As the expenditure increases it will become important that outcome measures to assess the results of strategies for prevention or intervention are developed and applied.

The arguments for and against special centres will continue. As 'there are few areas of paediatrics that have so rapidly expanded in clinical importance in recent years as the sexual abuse of children's it is important that all paediatricians are trained, willing, and able to diagnose this as well as other types of abuse. The danger of the special centre is that the problem is seen as someone else's, in 'the unit over there'. It is to be hoped that the Rainbow Centre proves as solid and permanent in reality as the concept is attractive and appealing.

\section{J HOBBS \\ St fames's University Hospital, \\ Beckett Street Leeds LS9 7TF}

1 Gough D, Boddy FA, Dunning N, Stone FH. A longitudina study of child abuse. Vol I. The children who were registered. Glasgow: Social and Paediatric Research Unit, University of Glasgow, 1987.

2 Frothingham TE, Barnett R, Hobbs CJ, Wynne JM. Child sexual abuse in Leeds and before and after Cleveland. Child Abuse Review (in press)

3 US Department of Health and Human Services. National study on the incidence of child abuse and neglect. Washington DC: US Department of Health and Human Services, 1988.

4 Mullen PE. The consequences of child sexual abuse. BMI 1991;303:144-5.

5 American Academy of Pediatrics: Committee on Child Abuse and Neglect. Guidelines for the evaluation of sexual abuse of children. Pediatrics 1991;87:254-60.

\section{Response from the authors}

Dr Hobbs raises several issues; some of these concern our data and some are of more general interest. We will try to answer the former and comment on the latter.

Firstly we agree with Dr Hobbs that our figures for child abuse would be low if they represented all cases of child abuse in our catchment area. In our paper we pointed out that "not all injured or abused children from this area are seen in the RLCH: staff in other hospitals and police stations within the area also see and diagnose child abuse'. We also believe that due to the difficulties in collating data from several sources within the hospital our figures are incomplete.

Secondly $\mathrm{Dr}$ Hobbs is surprised by the absence of neglect in our series. Again in the paper we try to make clear that failure to thrive, neglect, and emotionally abused children are investigated by medical paediatricians or the mental health team. These children were not 'picked up' in our study.

Thirdly he is surprised at the low level of confirmation of diagnosis, especially in sexual abuse. As stated in the text, in physical child abuse parents and carers of children on the child protection register are very diligent about referring children for examination if they are injured. The parents do this because they fear the accusation of neglect, the carers because they are anxious not to miss a repeat of the abuse. In sexual abuse we report 'clear physical findings of child sexual abuse' in 13\% of children examined. We did not analyse our findings for probability of abuse in view of the history given. We report 19 cases of positive physical findings which would corroborate but are not diagnostic of child sexual abuse. We do not know on what grounds the diagnosis of definite or probable child sexual abuse was made in Leeds. We doubt if Hobbs is comparing like with like. 